a paper sent by Dr B. K. Borisov (Institute of Biophysics, Moscow) to the Second International Conference on Strontium Metabolism held at Glasgow and Strontian between August 16 and 19. Dr Borisov analysed the skeletons of seventy-seven foetuses (aged between 3 and 8 months) and forty stillborn infants. The normal full-term infant contains about $10 \%$ of the calcium ingested by the mother during pregnancy, $3 \%$ of the stable strontium and less than $1 \%$ of the radioactive strontium. Dr Borisov's paper suggested that dietary stable and radioactive strontium, being in different chemical forms, might not be equally assimilable.

Three important lessons emerged from the conference. First, the risk of leukaemia or bone cancer (the chief reason for interest in fallout) now seems to be smaller than has sometimes been supposed. Dr Marvin Goldman (University of California, Davis) reported on large scale experiments using beagles, which have useful anatomical, physiological and metabolic similarities to man. Studies involving the administration of ${ }^{90} \mathrm{Sr}$, at various dose levels, over a period of twelve years, have now produced reliable dose-effect curves in the low dose region which has been the scene of speculation and controversy for many years. Dr Goldman's findings show that the damage to be expected from fallout in the human body is much smaller than has been suggested in some well publicized estimates based on extrapolation from fewer adequate data.

Second, and not surprisingly, governments are losing enthusiasm for systematic monitoring of fallout. The British programme of human bone monitoring is being terminated. This decision was influenced by the work of a group led by Dr J. H. Marshall (Argonne National Laboratory), who described a mathematical model of strontium metabolism which seems capable, with modifications, of predicting bone levels of ${ }^{90} \mathrm{Sr}$ from measurements on diet.

Third, the challenge of fallout has stimulated much important research in bone physiology and in metabolic disorders such as osteoporosis, as well as work on the mechanisms of intestinal absorption. The world's largest tracer experiment, though completely unplanned, still provides problems and opportunities for scientists and clinicians.

\section{ENTOMOLOGY \\ Conberra Congress}

from a Correspondent

SoME 1,500 entomologists from more than sixty countries met in Canberra between August 22 and 30 for the Fourteenth International Congress of
Entomology. The Australian National University provided excellent facilities, and Australian scientists, particularly those in the Entomology Division of the Commonwealth Scientific and Industrial Organization (CSIRO), whose head, Dr D. F. Waterhouse, was president of the congress, were responsible for the planning and smooth running of the programme.

Striking new discoveries are seldom reported to this type of gathering, but its programme did indicate interesting trends in contemporary entomology. Dr S. L. Tuxen, who retired from the office of President of the Permanent Committee after service of more than 20 years, pointed out that taxonomy, which had dominated most earlier meetings, now received little coverage (and comparatively small audiences for those papers that were included), even though all branches of entomology depended on the accurate determination of species. There were, however, many unofficial discussion groups among experts on different groups of insects, so this aspect of entomology was somewhat less neglected than the official programme might suggest.

The general impression was of a predominant interest in economic problems, with the largest audiences for symposia, often of a theoretical nature, on pest management and integrated control. At the opening of the plenary session, Dr E. F. Knipling (Agricultural Research Service, Beltsville, Maryland) discussed the significance of his own pioneer work, involving the use of sterile males to control pests in relation to biological control generally, and showed how repeated releases of large numbers of "beneficial" insects could be used almost as living insecticides. Dr P. W. Geier of CSIRO played a leading part in the organization of several symposia and sections concerned with pest control, although the congress was brought down to earth by Professor M. J. May (Imperial College), who criticized the "life table-life system-pest management" approach, and suggested that it had so far made little practical contribution to the actual business of pest control and to agriculture generally. There was throughout the meeting a general realization of the limitations of the value of many insecticides, although, as might be expected in a body of people with practical experience of pests and insect. borne diseases, little of the "ban them all" attitude which is so prevalent in lessinformed gatherings. At a symposium on "Insecticides and the Environment", Professor R. L. Metcalf (University of Illinois) and Professor H. T. Reynolds (University of California, Riverside) dealt constructively with the problems of developing and using new pesticides, and O. Starnes (Rockefeller Foundation, India) with the continuing need, even for DDT, in developing countries. Dr R. Goulding (Guy's Hospital Medical College) spoke of the significance (or lack of significance) of the universal traces of DDT and its metabolites in man, and Dr N.W. Moore (Monks Wood Experimental Station) reviewed the situation relating pesticides to wildlife conservation.

While the symposia dealing with general problems of pest management played to packed houses, the audiences for many of the afternoon sections, where those active in practical pest control described, often for the first time, their own contribution, were often disappointingly small. There was little apparent interest in laboratory studies in insect physiology, though insect behaviour, particularly as it relates to control, and to the use of pheromones,

\title{
Lambda Phage DNA Replication initiated in vitro
}

IN Nature New Biology next week (September 20) Klein and Powling describe a cell-free system which supports the initiation of replication of lambda phage DNA, and, although it is early days yet, this system holds considerable promise for those intent upon elucidating the biochemistry of this event. Genetic investigations have revealed that two lambda genes, $O$ and $P$, specify diffusible products that are required for the initiation of replication of the phage DNA. Mutants defective in either of these genes fail to replicate, but when Escherichia coli cells are doubly infected with one $O$ gene mutant strain and one $P$ gene mutant strain, complementation occurs in vivo and the phages replicate.

Lysates of such doubly infected cells, produced $7 \mathrm{~min}$ after infection, support the initiation of lambda DNA synthesis as do, albeit to a lesser extent, mixtures of lysates of cells singly infected with one or other mutant phage. Moreover, when rifampicin is added to such lysates, DNA synthesis is significantly inhibited because new rounds of replication cannot apparently be initiated even though daughter DNA chains initiated before the addition of the antibiotic are elongated normally in its presence. RNAase, by contrast, does not significantly inhibit initiation of DNA synthesis.

Whether this means that the role of RNA polymerase in the initiation of lambda DNA replication is structural rather than enzymatic is one of the several questions which may be answered by further exploiting this cell-free system. 